\title{
INSTITUTIONAL DESIGN IN THE SYSTEM OF STATE POLICY MEASURES FOR STIMULATING ECONOMIC GROWTH IN RUSSIA IN THE CONTEXT OF GEOPOLITICAL CHALLENGES
}

\author{
Elena Y. Zolochevskaya ${ }^{1}$, Tatyana P. Cherkasova ${ }^{2}$, Olga V. Mishurina ${ }^{3}$, \\ Yana E. Sivakova ${ }^{4}$
}

\begin{abstract}
This article analyzes the features of three groups of institutional factors: institutional and economic, institutional and political, and institutional and social. Influencing these factors by means of sound state policy can initiate economic growth on an innovative basis. An assessment of existing institutional barriers that act as constraints to economic growth in Russia is provided in the paper. In addition, the role of institutional design in optimizing the state policy for stimulating accelerated development and structural reorganization of the main development institutions is defined and an algorithm for implementing institutional design and its direction is proposed.
\end{abstract}

JEL Classification Number: E69, O10, O40; DOI: http://dx.doi.org/10.12955/cbup.v6.1206

Keywords: institutional design, modernization, economic system, state policy, public administration.

\section{Introduction}

The issue of innovative tools for accelerating economic growth rates is of particular importance in modern economic science. High and stable economic growth rates are one of the determinants of a country's competitiveness in the international arena and define the position of the economy and its rating in the global community.

The economic and political events of the last decade for Russia are as follows: a deep and comprehensive crisis, which is now becoming a worldwide phenomenon associated with the rapid fall in energy prices; a devaluation of the ruble against the world currency; an introduction of Western sanctions, as well as investment decline in the development of the Russian economy through the full or partial withdrawal of foreign companies from the domestic market; geo-economic and geopolitical instability of the entire world system; large-scale military conflicts; and a rivalry between old and new centers of power; new repartition of the world; among others. Overall, this actualizes the need to search for alternative tools for modernizing Russia's national economy.

In current terms, modernization is a comprehensive process of improvement aimed at ensuring progressive economic development. In economics, there are a large number of tools for stimulating economic growth (at macro, meso, and micro levels), a dominant part of which has been founded on researchers' conclusions that the fundamental reason for a diverging economy is the underdeveloped institutional environment and infrastructure. According to researchers, there is a direct relationship between the state of institutions and the characteristics of various economic processes (Nureev \& Latov, 2017). The search for new factors and the transformation of old ones in forming the institutional capacity of the state will help Russia to expand instrumental borders through state policy and align it with a new path of development. It is the structural transformations of institutions that will likely give the Russian government an opportunity to effectively stimulate economic growth in the country in the future.

In this regard, the strategic goals of state policy would need to be oriented not only towards overcoming the existing economic problems but also towards transitioning to a new quality of economic growth. The world is moving along the trajectory of transitioning to the "sixth technological

\footnotetext{
${ }^{1}$ South-Russian Institute of Management of Russian Presidential Academy of National Economy and Public Administration (SRIM RANEPA/Institute), nalogibuh@uriu.ranepa.ru

${ }^{2}$ Department of Economics and Entrepreneurship, Dean of the Faculty of Political Science at the South-Russian Institute of Management of Russian Presidential Academy of National Economy and Public Administration (SRIM RANEPA/Institute), ectheory@uriu.ranepa.ru

${ }^{3}$ Department of Economics and Entrepreneurship at the South-Russian Institute of Management of Russian Presidential Academy of National Economy and Public Administration (SRIM RANEPA/Institute), ectheory@uriu.ranepa.ru

${ }^{4}$ Department of Management at the South-Russian Institute of Management of Russian Presidential Academy of National Economy and Public Administration (SRIM RANEPA/Institute), menedjment@uriu.ranepa.ru
} 
order', and hence the future strategy of the social and economic development of the Russian Federation 2030 would need to be based on a complex of efficiently operating institutions.

The relevant impact of state policy on the economy, in particular, on stimulating the innovative type of growth of the national economy, is mainly hampered by institutional failures. This includes the tools, barriers, and pitfalls that are created because of the policy's underdevelopment or hypertrophy. The main objects of state policy in stimulating economic growth are institutional factors. However, these are not homogeneous and require tools and measures other than the state policy. Institutional factors can be divided into three aggregated groups.

The first group involves the institutional and economic factors that contribute towards economic systems displaying institutional balance. The behavior of economic players can ensure the sustainable operation of the national economy, in this case. The following distinguishes the most significant institutional and economic factors:

1. Innovation, research, and development (R\&D). An even stream of innovation, a growth model with inventions, a disaggregated model of knowledge instead of the aggregated one, investments in $R \& D$ and institutions that involve patents, the legal system, trademarks, trade and foreign investment. The higher the savings rate the higher the investment in R\&D. Innovators gain a monopoly, additional profit and this increases the investment in $\mathrm{R} \& \mathrm{D}$ and the range of products. The number of engineers in $R \& D$ affects the growth rate because it increases with their growth in numbers. Knowledge creates a positive externality (Cherkasova \& Aksenov, 2017).

2. Human capital. The human capital is represented by the knowledge received in the course of education, upgrade of skills, and retraining, as expressed in monetary terms (value form), which in itself represents a certain problem. Sometimes human capital is interpreted as an investment in knowledge, gaining of qualifications, and maintaining of health, that is, achieving a certain value in the human skill base and the human health reserves. In this case, human capital is proportional to the amount of investment allocated for these purposes and depends on the size of governmental spending on education and health. The presence of physical and human capital at a given level of natural resource capital is a necessary condition for growth.

3. Investment. Investments in both physical and human capital not only increase such capital and ensure economic growth, due to the 'multiplicative-accelerative effect' (as a rule, an increase in the production of the same quality and structure), but also create conditions for the introduction of innovations and changes in the quality of economic growth and the 'commodity-productive structure' of the national economy.

4. State policy having a dual role. On the one hand, state policy functions as a factor, and on the other, as an instrument. State policy as an institutional factor of economic growth is an administrative resource of the state, expressed in a complexity of powers of stimulating and sanctioned influence on the behavior of economic entities. Such an impact of the state can stimulate the development of priority sectors and the direction of the national economy on all levels.

The second group comprises the institutional and political factors. Political institutionalization is understood as the creation of political institutions and their strengthening, stabilization, and establishment in society. Political institutionalization traditionally concerns the institutionalization of norms, procedures, organizations, political parties and party systems, the opposition, the state, certain state bodies (e.g., the parliament or the president) the political regime, democracy, behavior, political practices, and the political system as a whole. In this regard, it is possible to distinguish the groups of institutional and political factors that can influence the economic growth of the country by their partial descriptions:

1. Public authority institutions. As is known, public authority institutions include institutions of legislative, executive, and judicial power at the federal and regional levels. Their influence on the economic growth of the state is determined by the political course (the development strategy, regulatory acts, goals, and principles of public administration);

2. Institutions of civil society. The most important institutions of civil society influencing the activities of public authority institutions are public organizations and associations (political 
parties, trade unions, and professional associations). Such interaction of political subjects helps form the trajectory of political processes in the country;

3. The institution of authority's elections. This group of elements of institutional and political factors includes a complex of legislative and regulatory acts governing the electoral process at all administrative levels of the state, the procedure for the formation of elective authorities, and bodies exercising control over the observance of the lawfulness in the course of election campaigns.

The third group comprises the institutional and social factors that include certain norms and values adopted by society. Cultural and religious values and their resulting behavioral features determine the configuration, the predicted changes, and the direction of the institution. Thus, discounting this group of factors could lead to negative consequences.

These listed groups of institutional factors may directly or indirectly affect economic growth. However, the list is not exhaustive. The initialization criterion also classifies these factors as internal and external and the tangibility criterion as tangible and intangible. It is important to take into account that the stimulatory impact on one of the factors does not initiate the acceleration of the rate of economic growth. However, to provide a stimulating effect, it is important to rank the available institutional factors of economic growth by the degree of dominance. The dominant factors can create a chain effect by initiating secondary factors.

The parameters of the institutional environment, in turn, are determined not only by the available factors of its development but also by existing institutional barriers and traps. Barriers can be divided into general and sectoral. General barriers to the institutional environment include:

- The variety of institutions and the lack of a model for their accounting and structuring;

- The formal and informal institutions that can influence the level of competition, creating entry barriers in certain industries or market segments, or establish direct prohibitions;

- The lack or complete absence of adequate assessments of the quality of the institutional environment in the regions of Russia;

- The institutional inertia of some institutions and the static nature of their development;

- The inconsistency and confrontation of formal and informal rules of institutional development;

- The barriers to entry and exit from formal institutions;

- Poor financing of institutions; and

- Weak civic engagement.

The following are the sectoral barriers to the institutional environment:

- The financial industry institutional barriers that involve the heterogeneity of economic players that causes a high degree of conflict between the wealthy and the underprivileged, the lower and upper classes, and the people and the power; the institutionalization of the interests of the minority. Higher-income groups of the population benefit from economic growth. Their income is mainly gained from the property, dividends, and wages.

- The polarity of mindsets that are attributed to the institutional problem of sociocultural orientation, which is reflected in the correlation of the value system (activism and fatalism, collectivism and individualism, paternalism and independence); the suppression of the interests of the results of formal institutionalization of interests, which contributes to the institutionalization of deviant forms of economic practices of subjects.

- Industrial barriers that include unstable consumer preferences; restrictions on access to resources; and state support of competitors.

The elimination of existing barriers and dysfunctions of the institutional environment, by means of stimulating the effect of its factors, requires new approaches to solve this problem. The modern world experience of institutional construction and modernization as the main interdisciplinary approach uses institutional design.

The goal of the institutional design is for the state to effectively form and develop models of economic institutions that are deliberately and purposefully introduced into the financial behavior of economic entities.

Institutional design includes a set of interrelated elements, the functioning of which ensures the optimization of the structure of the national economic system and its accelerated development 
following a structured trajectory. Institutional design involves a certain implementation algorithm, which includes the following:

- Historical analysis of institutional reforms in retrospect for the mapping of problematic areas;

- Objective assessment of the quality of existing institutions;

- Development of ways to transform institutions in accordance with the needs of society and the world as a whole;

- Analysis of specific regional factors affecting the process of institutional change;

- Development of normative and legal acts regulating the rights and obligations of each participant in the process; and

- Implementation and coordination of institutional reforms.

The institutional design can be considered the 'black box' in the system analysis. It is based on the interrelationship of elements within the system, where internal and external environments influence the incoming elements of the design process to yield the result (Figure 1).

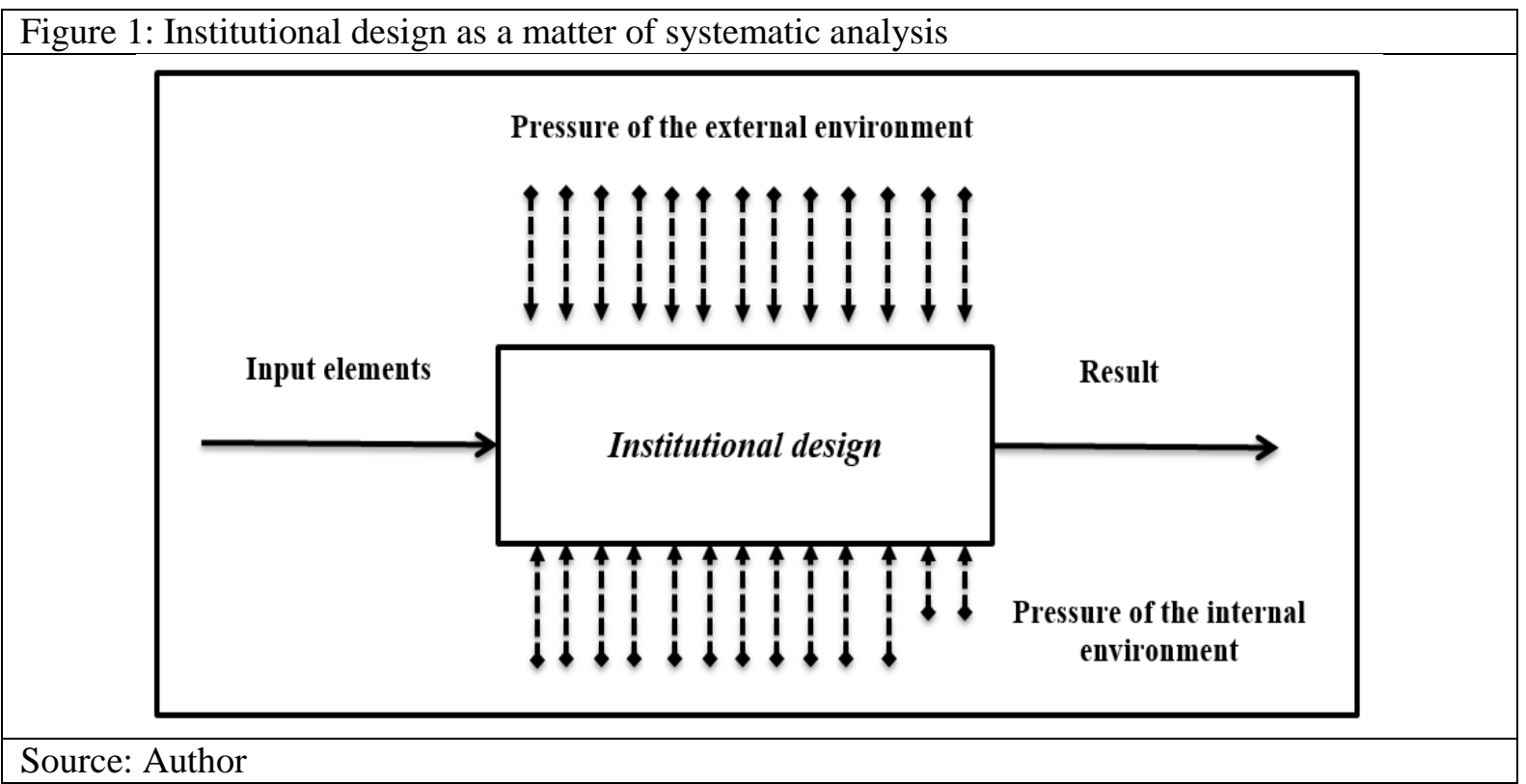

The complex implementation of the institutional design is impossible without creating and using the organizational principles of the state's regulation system. The state would act as a type of matrix, in the form of a 'development dilemma', and in two roles, one as coordinating manager and the other, as an equal participant in economic affairs. The role of the coordinating manager is justified where the country has sustained economic development rates and the functions of the state are limited to monitoring, coordinating, and regulating institutional processes. Where crisis phenomena negatively affect a large extent of the population's living standards, the state would be forced to exogenously impose an institutional order and act as a fully-fledged player rather than solely as one recognizing as creating conditions that fulfill institutional qualities formed spontaneously from 'below'.

In this regard, the institutional design of state policy can be based on three areas.

The first is the political and legal institutionalization of state policy. Institutionalization of state power is a basic political factor in modernizing the political system that influences political processes. Hence, state policy measures are aimed at changing the institutional design of government bodies. This is an important result of competition among political actors who have sufficient resources for impact, interests, and strategies of action.

The following are the priority tasks of state policy:

- Forming a stable system for political monitoring of the government's effectiveness, in general, and individual civil servants, in particular, using a mechanism of public reporting for voters and an opportunity to disqualify ineffective officials;

- Introducing an institutional mechanism for aggregating group interests of the national public, to allow public reflection of identified interests in the work of authorities and ensure 
transparency and functionality of the mechanism for making policy and management decisions;

- Increasing the degree of political and legal participation of citizens and the possibility of their control over the state policy being implemented by means of public discussions of legislative proposals at each level of government, initiation of legislation by citizens or public associations, and implementation of policy and management decisions using their expertise (over the internet space);

- Strengthening the political significance and expanding the functions of the public chamber of the Russian Federation and public chambers of the subjects of the federation, ombudsmen or commissioners for the protection of rights, and forming a democratic mechanism for their creation and publicly controlled schemes of the public councils in the executive bodies to increase the professionalism of their activities;

- Forming and developing partner models of the interaction of regional authorities with local self-government acting as a division of competences, responsibility, and resources for its implementation on the basis of subsidiarity;

- Institutionalizing the system of federalism when balancing centralization and decentralization, while preserving a priority of strengthening the state as a single integrated system that supports the equilibrium of legitimate interests of the subjects of the federation.

It is important to ensure the symmetry of the political status of regional authorities. This means reducing the imbalances in their resource base by both the regional and territorial policies and the scientifically substantiated and publicly approved transformation of federation constituents. Activating opportunities and strengthening the role of the Constitutional Court of the Russian Federation would preserve the political and legal unity and integrity of the territory of Russia.

Improving the quality and effectiveness of democracy in Russia is possible only with a balanced institutional development of the state and all its regions. The two basic principles are that the institutional development occurs on a democratic basis and coherence encompasses basic institutions of the federal state that are indispensable for preserving democracy and a competitive state. Ensuring institutional development of both the federation and its regions is vital within the framework of a single vector in forming democratic principles and norms. Hence, it is necessary to coordinate reforms of political institutions and interaction between subjects of the Russian politics (Ermolaev, 2016).

The second area is the economic institutionalization of state policy. To ensure movement along the ascending trajectory, it is necessary to radically transform the generally accepted norms and rules governing the financial activity of economic entities. Also, it is necessary to form a new hierarchy of relations to modernize the institutional form of the economic affairs system and integrate it on the basis of interoperability, complementarity, and interchangeability. On the one hand, the system becomes more manageable and predictable, and on the other hand, more complex with possible problems and contradictions.

The new system can be achieved by the following methods:

- Create an institutionally oriented model to develop the economic system; and

- Form an institutional framework for the interaction of economic entities.

The indicated methods assume the development and consistent implementation of state policy to stimulate economic growth by means of the following elements:

- Structural policy aimed at changing the structure of national production and shifting the focus from resource industries and trade to high-technology products such as micro- and nanoelectronics, robotics, aerospace production, and genetic engineering.

- An innovative policy aimed at creating a new market segment; food, personal, social, technological, technical innovations; modern management system; and institutionalized innovation activities that develop new sources of raw materials and markets for these purposes;

- An investment policy requiring investment marketing be established in Russia, in general, and regions, in particular, to promote Russia and its regions in market segments with the greatest resource potential; a positive investment image of each region and Russia as a whole and a 
resource fund that accumulates external resources for financing investment projects; and an organizational structure that ensures effective planning and development of investment in Russia;

- Industrial policy focused on increasing emphasis on the need to expand industrial parks and clusters in special economic zones oriented towards the external market; and

- Credit and financial policies aimed at accelerating economic growth by appointing a central bank responsible for tasks that minimize systemic risk within the financial sector, along with traditional functions; and creating a separate macroeconomic structure for supervisory and control functions with a special legal status as an institution of macroeconomic regulation that forms, distributes, and redistributes cash flows of the public sector and has responsibility for appropriate risks.

The third area is the social institutionalization of state policy. State policy needs to ensure unrestricted social mobility, both vertically and horizontally. Every economic entity needs an unimpeded opportunity to move within both the same institution and the entire institutional environment. Having no restrictions on the quantitative, qualitative, religious or moral choice of an institutional group is vital. Social institutions, in this case, act as certain channels of social mobility. These include family, education, economic and political organizations, the army, and the church. It is necessary to avoid isolation and barriers to create institutions related to ethnic or social class discrimination or any other characteristics of the individual.

\section{Conclusion}

In examining the nature of the impact of institutions' quality on a country's economic growth, it is important to note the need for government intervention in forming an institutional environment. It is recommended that the main instrument of such intervention involve a strategic institutional design that provides an internal policy of transitioning towards a trajectory of sustainable growth on an innovative basis under the current geopolitical challenges. A strong innovative thrust is needed to develop models of economic institutions that are decisively used in the financial behavior of economic entities.

\section{References}

Cherkasova, T.P., Aksenov, E.A. (2017). Contemporary tendencies in the formation of a system of public management institutions of innovation development in Russia // Public and Municipal Administration, Scientific Proceedings of SRIM RANEPA, 1, 55-61.

Ermolaev, S.A. (2016). Institutional foundations for development and conducting the industrial policy in the context of the import substitution policy in Russia, Innovations and Investments, 10, 200-203.

Ignatova, T.V., Cherkasova, T.P. (2011). Institutional concepts of economic growth and their modernization // State and municipal management, Scientific Proceedings of SRIM RANEPA, 2, 57-67.

Mau, V.A. (2016). Crises and lessons, Economy of Russia during a turbulence era. Moscow: the Gaidar Institute's Publishing House, $488 \mathrm{p}$.

Nureev, M.R., Latov, Y.V. (2017). Economic history of Russia (experience of institutional analysis). Moscow: Knorus Publ, $272 \mathrm{p}$. 